\title{
Investigation of Martian Surface and Interior Structures by Multiple Penetrator Probes
}

\author{
By Hiroaki SHIRAISHI ${ }^{1)}$, Ryuhei YAMADA ${ }^{2}$, Yoshiaki ISHIHARA $^{3)}$, Naoki KOBAYASHI ${ }^{1)}$, \\ Kojiro SUZUKI ${ }^{4}$, Masahiko HAYAKAWA ${ }^{1)}$ and Satoshi TANAKA ${ }^{1)}$ \\ ${ }^{1)}$ Institute of Space and Astronautical Science, JAXA, Sagamihara, Japan \\ ${ }^{2}$ RISE Project Office, National Astronomical Observatory, Mitaka, Japan \\ ${ }^{3)}$ Information Technology Research Institute, National Institute of Advanced Industrial Science and Technology, Tsukuba, Japan \\ ${ }^{4)}$ Department of Frontier Sciences, The University of Tokyo, Kashiwa, Japan
}

(Received June 28th, 2013)

\begin{abstract}
A new mission to investigate the Martian surface and interior structures using multiple penetrator probes is proposed. As a decelerator and a heat shield during the Martian atmospheric entry, a flare-type thin membrane aeroshell sustained by an inflatable torus frame will be applied to attain a compact and low-weight space vehicle. After separation from a carrier spacecraft, four identical penetrators will be deployed at intervals of a few hundreds kilometers from each other and penetrate into surface material up to a depth of 2 to 3 meters. Each penetrator installed seismometer system and a heat-flow probe will operate on the potential active regions in volcanism or seismic fault zones, associated with magmatic tectonics, crustal structure and current thermal state of Mars. A meteorological sensor package embedded in a backside of the aeroshell will observe the atmospheric structure during the entry, and it will possibly keep monitoring the Martian climate change on the surface. This paper describes the Martian penetrator design, the sequence of its deployment phase, onboard instruments, and their operational strategy.
\end{abstract}

Key Words: Mars, Penetrator, Aeroshell, Network Science

\section{Introduction}

Remote-sensing observations by the past and current orbital Martian spacecrafts have provided surface elemental abundances, mineral assemblages and geodetic data. Several of soft-landers and instrumented rovers have augmented the same sort of data with higher resolution. Investigation of the current internal structure of a terrestrial planet is needed to constrain the bulk composition, the initial thermal state and the following differentiation process. Knowledge of bulk composition of Mars has been mainly gleaned from the chemical and isotopic analysis of Martian meteorites ${ }^{1)}$ as well as in-situ measurement in major elements ${ }^{2}$ and determination of orbital dynamics ${ }^{3,4)}$, but they still remain to be poorly known. Geophysical observations such as seismometry and heat-flow measurement can provide important constraints on the internal structure and the abundance of major elements. For this purpose, network science requires an establishment of multiple surface stations operating concurrently on a planet. The past Viking 1 and Viking 2 Landers had tried to measure the Martian seismicity ${ }^{5)}$. The Viking 1 Lander failed to unlock a seismometer, whereas a similar seismometer on the Viking 2 was successfully operated for two years. However, the Viking 2 seismometer had not detected to confirmed seismic events or "marsquake" because of the relatively low sensitivity of the instrument and its location on the lander deck, which was subject to considerable disturbances from winds shaking the lander ${ }^{6}$. Recently, InSight (Interior Exploration using Seismic Investigations, Geodesy and Heat Transport) Mission has been selected as a NASA Discovery Program that would place a geophysical lander on Mars to study its deep interior ${ }^{7)}$. However, it will be a single station deployed in the lowland plain to the south of Elysium Mons ${ }^{8)}$, which means that it might be difficult to determine a location of earthquake focus and possible internal discontinuities.

A hard landing probe "penetrator" has been thought to be a very useful tool for the constitution of network stations on the planetary surface and subsurface, because it provides light-weight and cost-effective capabilities of deploying scientific instruments ${ }^{9}$. A long-lived network observation by penetrators gives unique possibilities for monitoring the global scale phenomena and for studies requiring simultaneous measurements (seismic, geodetic, magnetic, and meteorological observations) from several sites in one mission. And also, the penetrator will make it possible to deliver scientific instruments into the planetary surface for in situ chemical analysis and /or heat flow measurements without any drilling devices.

The major objective of this proposed mission is to investigate the Martian crust and upper mantle structure and their internal activity, which is considered to be a product of differentiation in silicate portion, by geophysical method. In particular, an accurate determination of the planet's crustal thickness at several geological settings is one of the primary goals of seismic experiment as an anchor for gravity/topography based model ${ }^{10)}$. A network observation by penetrators can also provide the information on the rate and distribution of internal seismic activity and possible volcanic activity, as well as the rate of meteoroid impacts on the surface. 
Martian thermal evolution and current state depend principally on the total abundance of radiogenic heat-producing elements $(\mathrm{U}, \mathrm{Th}, \mathrm{K})$ and their distributions in the crust and mantle. The value of surface heat flow is derived from the combination of the thermal conductivity and vertical temperature gradient, which is essential to understand the global average of thermal regime and to know the magmatic activity or convection inside the current mantle ${ }^{11)}$. In-situ heat-flow experiments on Mars have not been yet made on the past soft-lander missions. If the penetrators are deployed on the geological units different from the InSight landing site, it is useful to estimate the bulk abundance of radioactive heat-generating elements, with a support of global mapping data by gamma-ray spectrometer onboard Mars Odyssey spacecraft ${ }^{12)}$.

Another objective is to investigate the physical properties of a layer of fine-grained debris material (so-called 'regolith"), transport processes over the entire globe and its interaction with atmosphere. Almost all areas of Martian surface except both polar regions are covered with the granular material formed by intensive meteoroid impacts and frequent dust storms. The thermal inertia of planetary surface is the primary physical parameter that governs the daily thermal response of the surface layer to solar heating. It is closely related to the thermal conductivity or diffusivity of the surface materials and to the sedimentation of them. Therefore, we can compare in-situ thermal conductivity measurements with a global thermal inertia map by thermal emission spectrometer onboard Mars Global Surveyor ${ }^{13)}$. In addition to thermal conductivity sensors, the Mars penetrator will be also equipped with a shock accelerometer in order to measure the deceleration during penetration into the subsurface. Combined with the data of meteorological package installed in the aeroshell, it is useful for understanding of physical properties of surface layer and their diurnal/seasonal variations.

\section{Design of Mars Penetrator Module}

The penetrator module developed for the Moon's interior exploration consists of penetrator itself, a deorbit motor and attitude control system ${ }^{14)}$. The deorbit motor is fired for cancellation of orbital velocity, and attitude control system is used to reorient 90 degrees for vertical impact on the Moon. The most significant difference between Mars and Moon in environment is the existence of atmosphere or not. Thus, the Mars penetrator needs a decelerator and a heat shield during the atmospheric entry. On the past space program, two Martian penetrator system had been developed and launched. One is the Russian Mars-98 penetrator designed to decelerate using both a heat shield and a parachute and to land on the surface at almost the same as terminal velocity ${ }^{15)}$. The other is the NASA Deep Space 2 microprobe in USA, which shares the heat shield with the Mars Polar Lander, as a piggy back ${ }^{16)}$.

In this proposal, a flare-type membrane aeroshell sustained by an inflatable torus is applied and combined with the penetrator installed geophysical instruments as shown in Figure 1. The most significant advantage of the aeroshell is to reduce the aerodynamic heating during the atmospheric entry due to its low ballistic coefficient ${ }^{17)}$. In addition, even though dependent on the spacecraft configuration (in most cases), there is no need to equip with the conventional thermal protection system like an ablator or a heat-resistance material. Therefore, compared to the lunar penetrator module developed for the former LUNAR-A project ${ }^{14)}$, the Mars one would be very compact in size and light-weight.

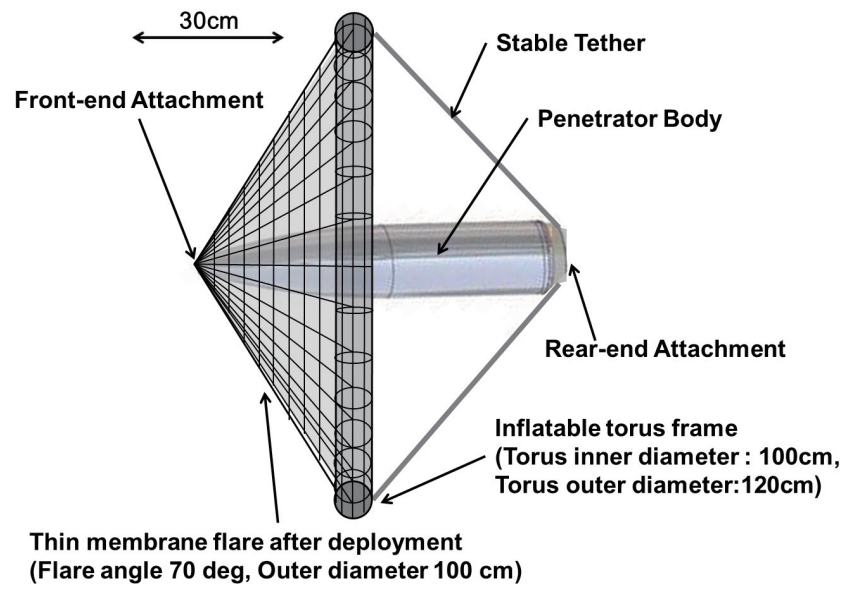

Fig. 1. Mars penetrator module using a flare-type membrane aeroshell sustained by an inflatable torus. Both the seismometer system and a heat flow probe are installed in the penetrator body and set under the ground. A meteorological package is embedded inside a backside of the aeroshell.

Concerning to the aeroshell system, a flight validation test was conducted using an S-310 sounding rocket of the Institute of Space and Astronautical Science, JAXA in the summer of 2012. In this reentry demonstration, a test vehicle installed a flexible aeroshell was launched. It reentered the atmosphere from an altitude of $150 \mathrm{~km}$ and inflated a torus frame in 1.2 meters diameter and 70 degrees flare angle, using an injecting gas under the vacuum and zero gravity conditions. After deployment of a thin membrane aeroshell accompanied by the torus frame, the test vehicle decelerated due to the aerodynamic force as planned and made a splashdown with success ${ }^{18)}$.

Table 1. Tentative parameters of Mars penetrator module.

\begin{tabular}{|l|l|}
\hline component name & Specification \\
\hline penetrator probe $^{(\#)}$ & $\begin{array}{l}800 \mathrm{~mm} \text { in length } \times \phi 140 \mathrm{~mm}, \\
14 \mathrm{~kg} \text { in weight }\end{array}$ \\
\hline $\begin{array}{l}\text { aeroshell system and } \\
\text { meteorological sensor } \\
\text { package }\end{array}$ & $\begin{array}{l}500 \mathrm{~mm} \times \phi 250 \mathrm{~mm} \text { (packed), } \\
\text { (unfolded), } 4 \mathrm{~kg} \text { in weight }\end{array}$ \\
\hline small thruster for deorbit & $<5 \mathrm{~kg}(\Delta \mathrm{V}=50 \sim 120 \mathrm{~m} / \mathrm{sec})$ \\
\hline $\begin{array}{l}\text { aeroshell attachment and } \\
\text { tether-like fastener }\end{array}$ & $<2 \mathrm{~kg}$ \\
\hline
\end{tabular}

(\#)Holding and release mechanism between the spacecraft and the penetrator module not included.

The Martian penetrator is a missile-shaped instrument carrier and is planned to have about $80 \mathrm{~cm}$ in length, $14 \mathrm{~cm}$ in diameter, and $14 \mathrm{~kg}$ in weight, which would be almost 
identical with the above-mentioned lunar penetrator. If the same aeroshell system as validated in the sounding rocket experiment would be applied for Mars penetrator, total weight of the module should be about $25 \mathrm{~kg}$, as shown in Table 1.

\section{Onboard Instruments}

Instruments onboard the penetrator main body for geophysical experiments are basically the same as the ones developed for the former LUNAR-A project, and some could be installed in the aeroshell. An outline of each prospective instrument is given as follows.

\subsection{Seismometer}

The seismometer is a short-period electromagnetic type with a natural period of about $1 \mathrm{sec}$; the output is proportional to the relative velocity between a moving coil and an internal magneto-static field ${ }^{19)}$. Its size is $50 \mathrm{~mm}$ in diameter, $50 \mathrm{~mm}$ in length, and $350 \mathrm{~g}$ in weight. Since the penetrators will not be emplaced in the Martian subsurface in an exactly vertical attitude, a rotation mechanism is installed to reorient the seismometer to the desired direction. Including the sensor electronics, the seismometer is $300-500$ times more sensitive than the Viking Lander short-period seismometer at a frequency of around $1 \mathrm{~Hz}^{6}$. In addition, the seismometer onboard penetrator could get out of the wind-induced seismic noise due to the subsurface installation, markedly different from the Viking mission. On the recent laboratory test, it was confirmed that the penetrator seismometer could operate under the low temperature condition of -50 degrees Celsius.

\subsection{Heat-flow probe}

The heat-flow value is to be determined by a combination of a thermal conductivity and a temperature gradient. Therefore, the heat-flow probe in the Mars penetrator consists of temperature sensors and thermal conductivity sensors ${ }^{20)}$. Absolute temperature sensors made of platinum resistance are used for temperature measurement inside the penetrator body and K-type thermo-couple sensors are installed peripheral to the penetrator body. Some of the thermo-couple sensors are also used for the thermal conductivity measurement; they each have a thin sheet-shaped heater attached on the interface between the penetrator and regolith. The thermal conductivity of the Martian regolith can be estimated from the temperature variation associated with the heat output from the sheet-shaped heaters considered as a point source.

\subsection{Accelerometer and tiltmeter}

The Martian penetrator is equipped with a shock accelerometer and a tiltmeter. The former is used to measure the deceleration during penetration into the Martian surface. The record of the accelerometer gives the impact velocity and the penetration path length by integrating with time. The tiltmeter is used to know the attitude of the penetrator that comes to rest in the surface layer. These data are important for the data reduction of the seismic and the thermal experiment, as well as for the operational plan.

\subsection{Meteorological package}

The primary objective of meteorological package embedded in a backside of the aeroshell is a measurement of atmospheric conditions such as pressure, temperature, wind speed, and magnetic field during the entry. If possible, after touchdown on the surface, the meteorological sensors will continue to monitor the environment around the deployment site. The diurnal/seasonal variation in these monitoring data would be useful for data reduction of seismic and heat-flow data.

\subsection{Monitoring camera}

An optical camera onboard the spacecraft will search for impact craters and landslides around the network constituted by multiple penetrator probes, which should occur during the observation period of penetrator seismometer. These detected landmarks will be available for seismological study as known earthquake foci. And also, it takes images of control points of Mars' coordinate system ${ }^{21)}$ to correct the spacecraft's flight orbit and to determine the precise location of the buried penetrator, with a support of the Doppler measurement.

\section{Deployment Sequence of Penetrator Module}

Compared to the past and current Martian soft-landers, the penetrator system proposed in this paper has the flexibility to allow a wider range of deployment site in elevation and has an advantage not to be easily influenced by a low-level wind shear. The potential region to constitute a penetrator network is the Central Elysium Planitia, which is one of the youngest volcanic provinces at the Martian surface and locates in the range $150^{\circ} \mathrm{E}$ to $180^{\circ} \mathrm{E}$ in longitude and $5^{\circ} \mathrm{S}$ to $10^{\circ} \mathrm{N}$ in latitude. According to recent detailed mapping and crater counting data by several Martian spacecrafts, this region is characterized by both long lava flows of low surface roughness and the occurrence of large shield volcanoes ${ }^{22)}$. It suggests that the volcanic activity in this region should have continued intermittently over the last 200 million years. Another candidate for landing site is the Tharsis region. Knapmeyer et al.(2006) compiled an inventory of compressional and extensional tectonic faults on the basis of Mars Orbiter Laser Altimeter (MOLA) shaded relief map, and simulated spatial distribution and level of Martian seismicity ${ }^{23)}$. These working models indicate that most seismic events are expected on the Tharsis shield. If the seismic network is deployed around this region, the seismic experiment will be optimized to get the information of Martian seismicity and crust/upper mantle structure. From a thermal point of view, the recent volcanic activity on the Elysium (and to a lesser extent, the northern part of Tharsis province) implies that the heat flow is considerably high and that magma chambers might be still extant underneath the solidified lava flow sheet. Therefore, the thermal experiment by penetrator probes can provide the constraints on the abundance of radiogenic heat-producing elements, temperature profile inside the crust, depleted mantle contribution to the total heat flow, and possible mantle convection. For these reasons, either of Elysium and Tharsis 
regions is adapted for a potential site of penetrator network and geophysical observation. Eventually, to arrange the length of baseline and the appropriate placement of penetrator network, we should refer to the information on the seismic activity and the ambient noise level obtained on the preceding InSight mission.

A 3-axis stabilized satellite with four penetrator modules, which should play roles of a carrier of penetrator modules and of a data-relay orbiter, is assumed to revolve in a circular orbit of $300 \mathrm{~km}$ altitude around Mars. Before separation from the spacecraft, a small thruster would be mounted on the front end of penetrator module and the aeroshell would be folded around the penetrator body. A sequence of the Martian atmospheric entry is schematically shown in Fig. 2, and details are as given below.

(1) The spacecraft releases each penetrator module with a spin rate of $\sim 1 \mathrm{~Hz}$ and a tangential velocity of $\sim 1 \mathrm{~m} / \mathrm{sec}$ so as to avoid a collision.

(2) The small thruster or retro-motor $(\Delta \mathrm{V}=50 \sim 120 \mathrm{~m} / \mathrm{sec})$ will be burned out to make a de-orbit and to orient toward the Martian surface.

(3) After separation of the thruster, the aeroshell will be unfolded and deployed by injecting gas into the inflatable torus with a support of a centrifugal force due to a spin motion of the module itself.

(4) Although the penetrator module may enter the atmosphere with a large attack angle due to no installation in the attitude control system, it is expected to turn toward an attitude in zero angle of attack when the aerodynamic force acts on the stretched-out aeroshell.

(5) The aeroshell will be ejected from the penetrator body before touchdown, and the only penetrator penetrates into the surface layer of Mars, with a velocity of 250 to 300 $\mathrm{m} / \mathrm{sec}$.

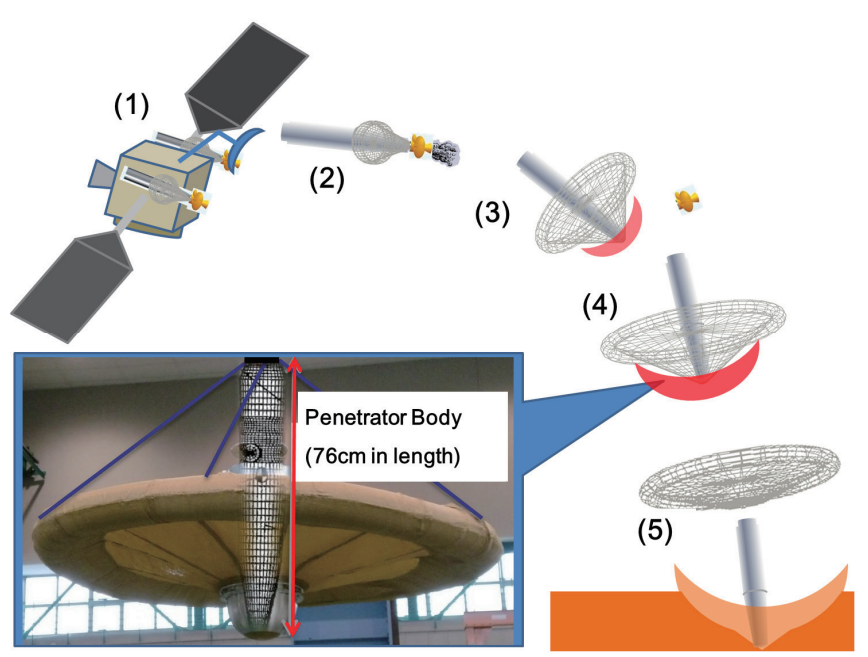

Fig. 2. Schematic of an entry of penetrator module from a Martian orbit. The details of figures in parentheses are described in the text. At the lower left, the penetrator body is superimposed to scale on the photo of the unfolded aeroshell flown on the sounding rocket.
We investigate numerically the impact conditions, flight trajectory, aerodynamic pressure, and heating conditions of the module after deployment of membrane aeroshell from an altitude of $300 \mathrm{~km}$. In the following analyses, the parameters are assumed to be the same as the specification of aeroshell with a diameter of $1200 \mathrm{~mm}$ flown on the sounding rocket experiment $^{17,18)}$.

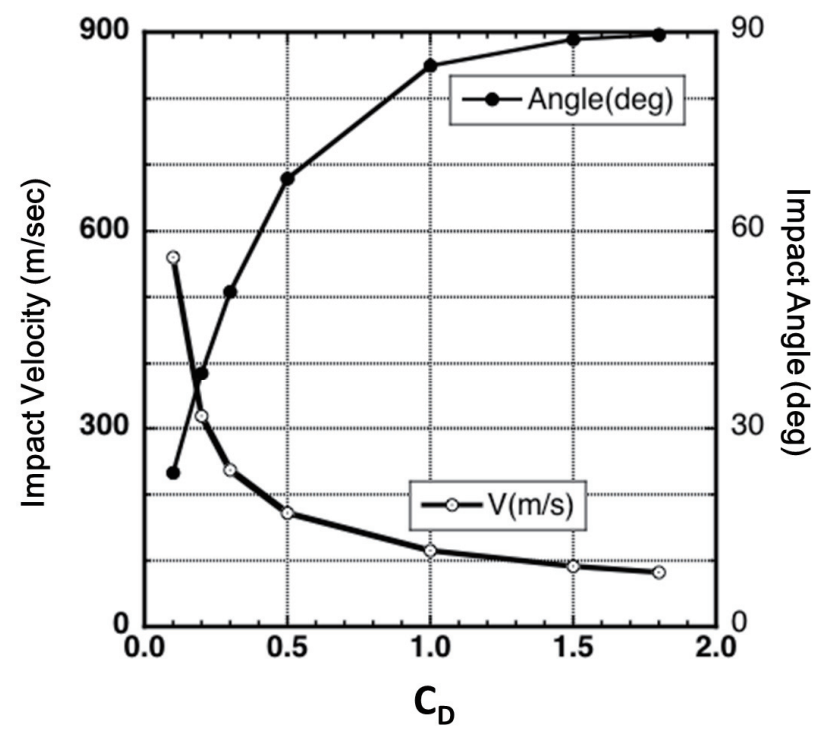

Fig. 3. Numerical results of impact angle and impact velocity as a function of drag coefficient $C_{D}$. It is assumed that the entry altitude is 300 $\mathrm{km}$ and $\Delta \mathrm{V}$ of small thruster is $50 \mathrm{~m} / \mathrm{sec}$. (Reprint from Figure 4 of Shiraishi et al., 2012 24$)$ )

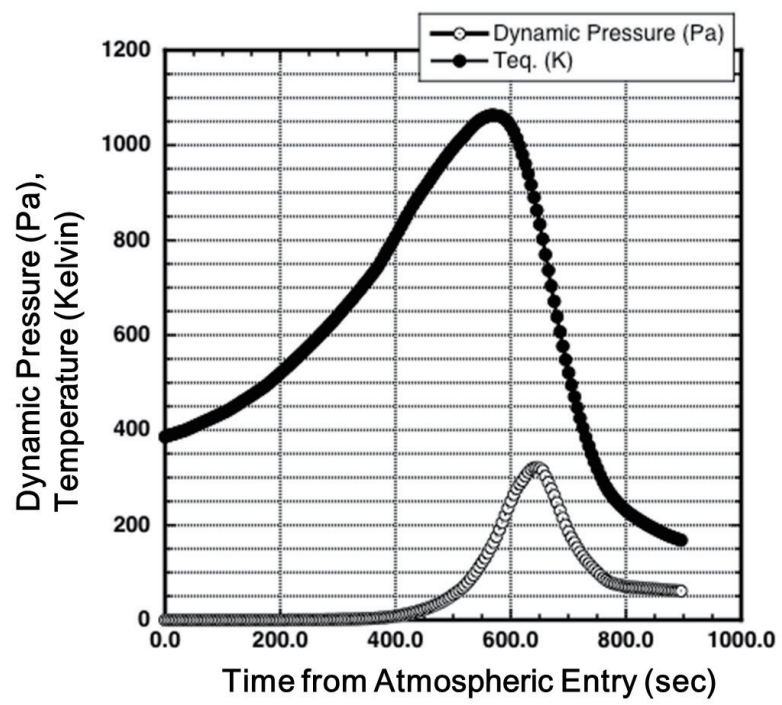

Fig. 4. Time history of dynamic pressure and surface temperature at the front end of aeroshell during the atmospheric entry in case of $C_{D}=1.5$. (Reprint from Figure 4 of Shiraishi et al., 2012 ${ }^{24)}$ )

Fig. 3 indicates that the larger drag coefficient of unfolded aeroshell can turn the module at the right angle to the surface and make it fairly slow down. The inflatable torus could keep the shape as long as the inner pressure is higher than the ambient pressure at all the time during the atmospheric entry. 
On the contrary, when the inner absolute pressure in the inflatable torus would be set less than ambient pressure at any altitude, we could control the aerodynamics of penetrator module such as deceleration trajectory, impact angle and impact velocity due to the shrinkage of membrane flare and the reduction of conical angle, even though dependent on the elevation of deployment site. That is, it needs to adjust the inner pressure in the torus tube, flare angle along the way and the separation altitude of aeroshell, so that the penetrator hits on the surface vertically as possible, with a velocity of 250 $\mathrm{m} / \mathrm{sec}$ or more.

Fig. 4 shows that the aeroshell will experience a hypersonic free flight where aerodynamic pressure is $400 \mathrm{~Pa}$ and the moderate aerodynamic heating at stagnation is about 1100 Kelvin. The current design of aeroshell could survive sufficiently the maximum pressure and temperature during entry.

\section{Spacecraft and Penetrator Operation}

Due to the limited number of penetrator modules and inherent ability of seismometer onboard, each penetrator will be deployed at a few hundred kilometers apart and record the deceleration-time history to come to rest into the surface layer up to 2 to 3 meters. And then, it will measure the interior and exterior temperature fields. After the achievement of neutral position of seismometer pendulum with gimbal mechanism, the ground motion will be recorded for signals larger than a threshold level to reduce power consumption in the nominal operation mode. The threshold level and recording duration can be changed later in remote operation by command from the ground station, depending on the seismic activity of Mars including events induced by meteoroid impacts.

The penetrator UHF-band tele-communication system, which is mounted on the rear end of penetrator body, relays stored data back to the earth via the spacecraft which passes overhead approximately once every 2 hours. During the communication link, the Doppler measurement will be performed between the spacecraft and the buried penetrator. Using the possible number of transmissions and the geometry of passes, we can determine the accurate location of penetrator deployment site relative to the control points of Mars, as well as making a time correction of penetrator's onboard clock. This is because we need to know both the origin time and the focus of an earthquake event for the analysis of seismic data.

\section{Technical Issues in Development}

The most critical issue of penetrator design is the thermal environment on Mars. The penetrator probes are likely to stay colder than -40 degrees Celsius. A lithium-thionyl primary battery developed for the lunar penetrator must be operated under the fairly cold conditions. In addition, adequate measures for thermal insulation and low power consumption should be taken for long-term observation, as well as a trade-off study between the frequency in use of transmitter and a required data volume to consume the battery efficiently. However, the mission lifetime is assumed to be three months at least and six months at maximum with the presently-allocated battery capacity. Another technical concern is the telecommunication system design, which might be more challenging than those of the Moon because it should take into account the uncertain dielectric properties of the Martian regolith. The last one is the attachment and release mechanism between the aeroshell and penetrator itself. Though the impact angle on the Martian surface is nominally designed to be vertical with a velocity of 250 to $300 \mathrm{~m} / \mathrm{sec}$ and with zero attack angle, there is a possibility that the penetrator will hit on the surface with an oblique impact and/or a finite attack angle. This will possibly occur due to an insufficient regulation of dynamic balance, a slight error of an explosive device in the release mechanism and an asymmetrical shape of the aeroshell just before detachment.

\section{Conclusions}

Martian exploration by multi penetrator probes with a flare-type thin membrane aeroshell as a decelerator and a heat shield is proposed. The seismic observation by penetrator network can determine the crustal thickness, which should be the primary product from the magma ocean in the early history of Mars or the massive accumulation of incessant silicate volcanism. The heat-flow experiment provides the essential data to estimate the bulk abundance of radioactive heat-generating elements and their distribution between the crust and mantle, which should constraint the magnitude of magmatic activity and the pattern of mantle convection. After detachment from the penetrator, the aeroshell with built-in meteorological sensors will continue the environmental monitoring as ancillary data required for seismic and thermal experiments.

\section{References}

1) Wänke, H. and Dreibus, G.: Chemical Composition and Accretion History of Terrestrial Planets, Phil. Trans. R. Soc. Lond. A325 (1988), pp.545-557.

2) McSween, Jr. H. Y., Grove, T. L. and Wyatt, M. B.: Constraints on the composition and petrogenesis of the Martian crust, $J$. Geophys. Res., 108, E12 (2003), 5135, doi:10.1029/2003JE002175.

3) Yoder, C. F., Konopliv, A. S., Yuan, D. N., Standish, E. M. and Folkner, W. M.: Fluid Core Size of Mars from Detection of the Solar Tide, Science, 300 (2003), pp. 299-303.

4) Folkner, W. M., Yoder, C. F., Yuan, D. N., Standish, E. M. and Preston, R. A.: Interior Structure and Seasonal Mass Redistribution of Mars from Radio Tracking of Mars Pathfinder, Science, 278 (1997), pp. 1749-1752.

5) Anderson, D. L., Miller, W. F., Latham, G. V., Nakamura, Y., Toksöz, M. N., Dainty, A. M., Duennebier, F. K., Lazarewicz, A. R., Kovach, R. L. and Knight, T. C .D.: Seismology on Mars, J. Geophys. Res., 82 (1977), pp. 4524-4546.

6) Nakamura, Y. and Anderson, D. L.: Martian wind activity detected by a seismometer at Viking Lander 2 site, Geophys. Res. 
Lett., 6 (1979), pp. 499-502.

7) Banerdt, W. B., Smrekar, S., Hurst, K., Lognonné, P., Spohn, T., Asmar, S., Banfield, D., Boschi, L., Christensen, U., Dehant, V., Folkner, W., Giardini, D., Goetz, W., Golombek, M., Grott, M., Hudson, T., Johnson, C., Kargl, G., Kobayashi, N., Maki, J., Mimoun, D., Mocquet, A., Morgan, P., Panning, M., Pike, W. T., Tromp, J., van Zoest, T., Weber, R., Wieczorek, M. and the InSight Team.: InSight : A Discovery Mission to Explore the Interior of Mars, 44 ${ }^{\text {th }}$ Lunar and Planet. Sci. Conf., (2013), Abstract \#1915.

8) http://insight.jpl.nasa.gov/newsdisplay.cfm?Subsite_News_ID=33 931\&SiteID $=8$

9) Lorenz, R. D.: Planetary penetrators: Their origins, history and future, Adv. Space Res., 48 (2011), pp.403-431.

10) Neumann, G. A., Zuber, M. T., Wieczorek, M. A., McGovern, P. J., Lemoine, F. G. and Smith, D. E.: Crustal structure of Mars from gravity and topography, J. Geophys. Res., 109 (2004), E08002, doi:10.1029/2004JE002262.

11) Hahn, B. C., McLennan, S. M. and Klein, E. C.: Martian surface heat production and crustal heat flow from Mars Odyssey Gamma-Ray spectrometry, Geophys. Res. Lett., 38 (2011), L14203, doi:10.1029/2011GL047435.

12) Taylor, G. J., Stopar, J. D., Boynton, W. V., Karunatillake, S., Keller, J. M., Brückner, J., Wänke, H., Dreibus, G., Kerry, K. E., Reedy, R. C., Evans, L. G., Starr, R. D., Martel, L. M. V., Squyres, S. W., Gasnault, O., Maurice, S., d'Uston, C., Englert, P., Dohm, J. M., Baker, V. R., Hamara, D., Janes, D., Sprague, A. L., Kim, K. J., Drake, D. M., McLennan, S. M. and Hahn, B. C.: Variations in K/Th on Mars, J. Geophys. Res., 112 (2007), E03S06, doi:10.1029/2006JE002676.

13) Jakosky, B. M., Mellon, M. T., Kieffer, H. H., Christensen, P. R., Varnes, E. S. and Lee, S. W.: The thermal inertia of Mars from the Mars Global Surveyor Thermal Emission Spectrometer, $J$. Geophys. Res., 105, E4, (2000), pp. 9643-9652.

14) Shiraishi, H., Tanaka, S., Fujimura, A. and Hayakawa, H.: The present status of the Japanese Penetrator Mission : LUNAR-A, Adv. Space Res., 42 (2008), pp.386-393.

15) Surkov, Y. A. and Kremnev, R. S.: Mars-96 mission: Mars exploration with the use of penetrators, Planet. Space Sci., 46 (1998), pp.1689-1696.

16) Smrekar, S. E., Catling, D., Lorenz, R., Magalhães, J., Moersch,
J., Morgan, P., Murray, B., Presley, M., Yen, A., Zent, A. and Blaney, D.: The DS-2 Mars Microprobe Mission, J. Geophys. Res., 104, E11, (1999), pp. 27013-27030.

17) Yamada, K., Abe, T., Suzuki, K., Imamura, O., Akita, D. and MAAC research and development group.: Reentry Demonstration Plan of Flare-type Membrane Aeroshell for Atmospheric Entry Vehicle using a Sounding Rocket, Proceeding of $21^{\text {st }}$ AIAA Aerodynamic Decelerator Systems Technology Conference and Seminar (2011), AIAA2011-2521.

18) Yamada, K., Nagata, Y., Abe, T., Suzuki, K., Imamura, O., Akita D. and MAAC research and development group.: Reentry Demonstration of Flare-type Membrane Aeroshell for Atmospheric Entry Vehicle using a Sounding Rocket, Proceeding of AIAA Aerodynamic Decelerator Systems Conference (2013), AIAA2013-1388

19) Yamada, R., Yamada, I., Shiraishi, H., Tanaka, S., Takagi, Y., Kobayashi, N., Takeuchi, N., Ishihara, Y., Murakami, H., Yomogida, K., Koyama, J., Fujimura, A. and Mizutani, H.: Capability of the penetrator seismometer system for lunar seismic event observation, Planet. Space Sci., 57 (2009), pp.751-763.

20) Tanaka, S., Yoshida, S., Hayakawa, M., Horai, K., Fujimura, A. and Mizutani, H.: Development of the heat flow measurement system by the LUNAR-A penetrators, Adv. Space Res., 23 (1999), pp.1825-1828.

21) Archinal, B. A., Lee, E. M., Kirk, R. L., Duxbury, T. C., Sucharski, R. M., Cook, D. A. and Barrett, J. M.: A New Mars Digital Image Model Control Network, $\mathrm{XX}^{\text {th }}$ Congress of the International Society of Photogrammetry and Remote Sensing, (2004), Commission IV, WG IV/9, 12-23 July, Istanbul, Turkey.

22) Vaucher, J., Baratoux, D., Mangold, N., Pinet, P., Kurita, K. and Grégoire, M.: The volcanic history of central Elysium Planitia: Implications for martian magmatism, Icarus, 204 (2009), pp.418-442.

23) Knapmeyer, M., Oberst, J., Hauber, E., Wählisch, M., Deuchler, C. and Wagner, R.: Working models for spatial distribution and level of Mars' seismicity, J. Geophys. Res., 111 (2006), E11006, doi:10.1029/2006JE002708.

24) Shiraishi, H., Yamada, S., Ishihara, Y., Kobayashi, N., Suzuki, K. and Tanaka, S.: Investigation of Martian surface and internal structure by penetrator probes, Planetary People, 21 (2012), pp.283-288 (in Japanese). 